\title{
Zoon's balanitis with mucinous metaplasia: A case report and review of literature
}

\author{
Jin-Ping Lai ${ }^{{ }^{*}}$, Edward W. Cowen ${ }^{2}$, Jere B. Stern ${ }^{1}$, Leomar Y. Ballester ${ }^{1}$, Emily Y. Chu ${ }^{2}$, \\ Rodolfo E. Chirinos ${ }^{3}$, Richard W. Childs ${ }^{4}$, Chyi-Chia Richard Lee ${ }^{1 \#}$ \\ ${ }^{1}$ Laboratory of Pathology, National Cancer Institute, National Institutes of Health, Bethesda, USA \\ ${ }^{2}$ Dermatology Branch, National Cancer Institute, National Institutes of Health, Bethesda, USA \\ ${ }^{3}$ Department of Dermatology, Georgetown University Hospital, Washington DC, USA \\ ${ }^{4}$ Hematology Branch, National Hear, Lung, and Blood Institute, National Institutes of Health, Bethesda, USA \\ Email: laijxx@,cshs.org, cowene@mail.nih.gov, Leo.ballester@mail.nih.gov, childsr@nhlbi.nih.gov, jerebstern@juno.com, \\ "leechy@mail.nih.gov
}

Received 28 November 2012; revised 31 December 2012; accepted 12 January 2013

Copyright (C) 2013 Jin-Ping Lai et al. This is an open access article distributed under the Creative Commons Attribution License, which permits unrestricted use, distribution, and reproduction in any medium, provided the original work is properly cited.

\begin{abstract}
Mucinous metaplasia of the squamous epithelium of the glans penis is very rarely seen in the setting of Zoon's balanitis. We report a case of 40 year old male with a past medical history of paroxysmal nocturnal hemoglobinuria, status-post allogeneic hematopoietic cell transplantation from an HLA-matched sibling 6 years prior to evaluation, complicated by oral and cutaneous chronic graft-versus-host disease. Mucinous metaplasia was confirmed by PAS and Mucin stains, and plasmacytosis was confirmed by immunohistochemistry for CD138 and MUM1 markers. Kappa and Lambda immunostains revealed a polyclonal pattern. The etiology of zoon's balanitis as well as the significance of mucinous metaplasia in these setting are unclear and need to be further investigated.
\end{abstract}

Keywords: Bone Marrow Transplant; Squamous Cell Carcinoma; Erythroplasia of Querat; Graft versus Host Disease

\section{INTRODUCTION}

Zoon's balanitis is an idiopathic, benign condition affecting the male genitalia that often presents as a solitary, persistent plaque on the glans penis of uncircumcised, middle-aged or older men. Mucinous metaplasia of the squamous mucosa in Zoon's balanitis is exceedingly rare —only seven cases occurring in elder men have been re-

\footnotetext{
*Jinping Lai is currently affiliated to the Department of Pathology and Laboratory Medicine, Cedars-Sinai Medical Center, Los Angeles, USA.

${ }^{\#}$ Corresponding author.
}

ported in the English literature [1-4], and the pathogenic association between the two processes is unknown.

\section{PATIENT'S INFORMATION AND METHODS}

A 40-year-old Nepalese, uncircumcised male presented with a history of dryness of the glans penis for the previous two years with associated loss of skin over the affected area. The lesion had been treated with clobetasol ointment with intermittent improvement. His past medical history includes allogeneic hematopoietic stem cell transplantation from a 6/6 HLA-matched sibling for paroxysmal nocturnal hemoglobinuria 6 years prior. On examination, a non-healing, shiny, well-demarcated erythematous plaque affecting the glans penis and distal shaft was seen (Figure 1(a)). The clinical differential included erythroplasia of Querat, squamous cell carcinoma, and chronic graft-versus-host disease.

Immunohistochemistry: Paraffin embedded tissue sections $(5 \mu \mathrm{m})$ were deparaffinized through xylene and graded alcohols. Immunohistochemical staining for CD138 (Oxford, UK, 1:10), MUM1 (Perugia, Italy, 1:2), Kappa (Dako, 1:32,000), Lambda (Dako, 1:32,000), IgG4 and IgG (Dako, 1:16,000), CD3 (Novacastra, UK, $1: 30$ ) and CD20 (Dako, 1:80) was performed following heatinduced epitope retrieval using target retrieval solution, low $\mathrm{pH}$ (DAKO) [5]. Slides were incubated in Triswith 3\% goat serum for $15 \mathrm{~min}$ and then incubated for 1 to $2 \mathrm{~h}$ at room temperature with primary antibody. Detection was carried out using an automated slide stainer (DAKO; Autostainer) with a horseradish peroxidase $/ 3,3$ '-diami- nobenzidine polymer-based detection system (DAKO; Envision+). 


\section{RESULTS}

A punch biopsy from the glans penis revealed a band like dense inflammatory infiltrate with plasma cells in the superficial dermis. Foci of goblet cells within the nonkeratinizing squamous epithelium, consistent with mucinous metaplasia, were observed (Figure 1(b)). Marked plasmacytosis in the superficial mucosa was noted (Figure 1(c)). The presence of goblet cells was confirmed by positive cytoplasmic staining for PAS (Figure 1(d)), Colloidal iron, Mucicarmine, and Alcian-blue (data not shown). Special stains including GMS, PAS, and Warthin Starry were negative for fungal organisms and Spirochetes (data not shown). Histologic features diagnostic of squamous cell carcinoma were not observed. Immunohistochemistry for CD20, CD3, CD138, MUM1, Kappa, Lambda, IgG and IgG4 was performed. Marked plasmacytosis was highlighted by the CD138 and MUM1 stains (Figures 2(a)-(b)). Kappa and Lambda stains showed a polyclonal pattern (Figures 2(c)-(d)). There were some $\mathrm{CD} 20$ and $\mathrm{CD} 3$ positive $\mathrm{B}$ and $\mathrm{T}$ cells admixed with plasma cells. Eighteen IgG4 positive cells/high power field were identified with an IgG4/IgG less than $30 \%$.

\section{DISCUSSION}

Zoon's balanitis, also known as balanitiscircumscriptaplasmacellularis or plasma cell balanitis, is an idiopathic condition characterized by a heavy stromal inflammatory infiltrate composed of mainly plasma cells. Although circumcision is curative in most of cases of Zoon's balanitis, other therapeutic options including laser ablation, imiquimod, and topical calcineurin inhibitors have also been described $[5,6]$. In the present case, the patient was treated with clobetasol ointment with limited improvement, followed by tacrolimus $0.1 \%$ ointment with partial improvement.

Mucinous metaplasia of the squamous epithelium of glans penis is very rarely seen in the setting of Zoon's balanitis. To our knowledge by "Pubmed" search of "metaplasia" and "balanitis", only seven cases are reported in the English literature (Table 1), with this being the 8th reported case. The current patient is the first reported case following allogeneic hematopoietic stem cell transplantation and is also remarkable for the young age of onset compared to the previously reported cases.Polycolonal pattern of plasmacytosis is the main infiltrating pattern with some IgG4 cells identified. The (a)

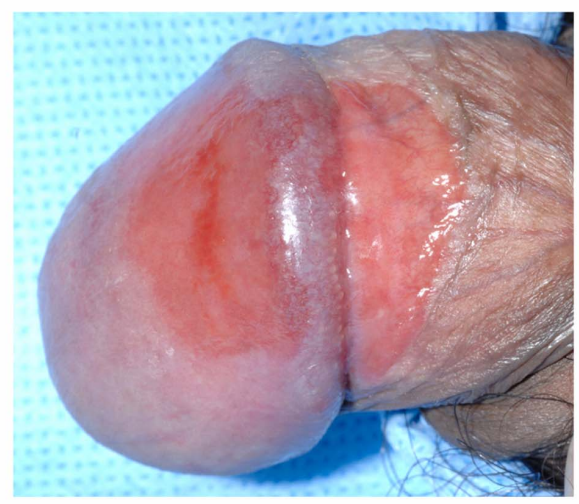

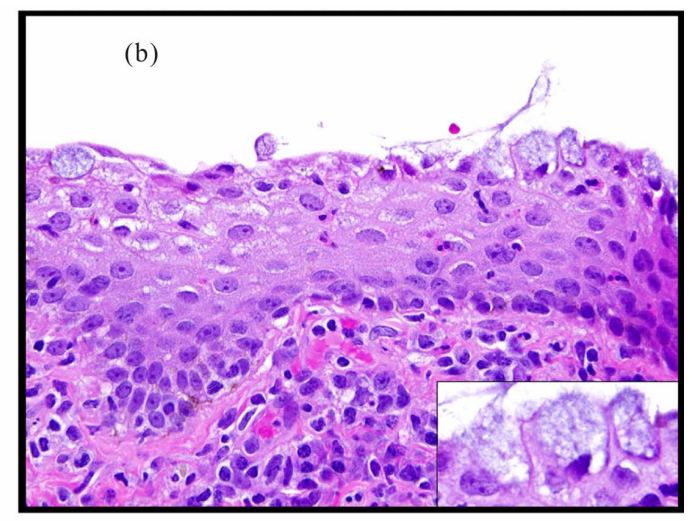

(d)

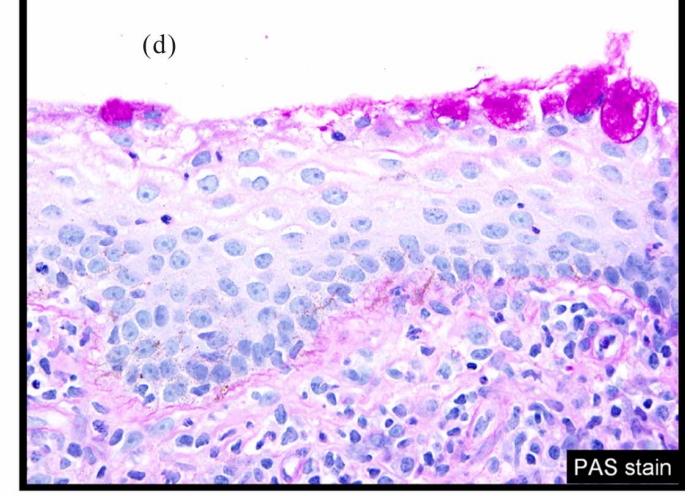

Figure 1. Gross appearance of Zoon's balanitis prior to biopsy. There is a shiny, well-demarcated erythematous plaque affecting the glans penis and distal shaft (a). H\&E section of the biopsy from glans penis showing goblet cells at the surface of the non-keratinizing squamous epithelium $(\times 200,(b))$ and patchy plasma cell infiltrate at the superficial dermis $(\times 200$, (c)). PAS stain highlights many goblet cells at the surface of squamous epithelium $(\times 200$, (d)). 

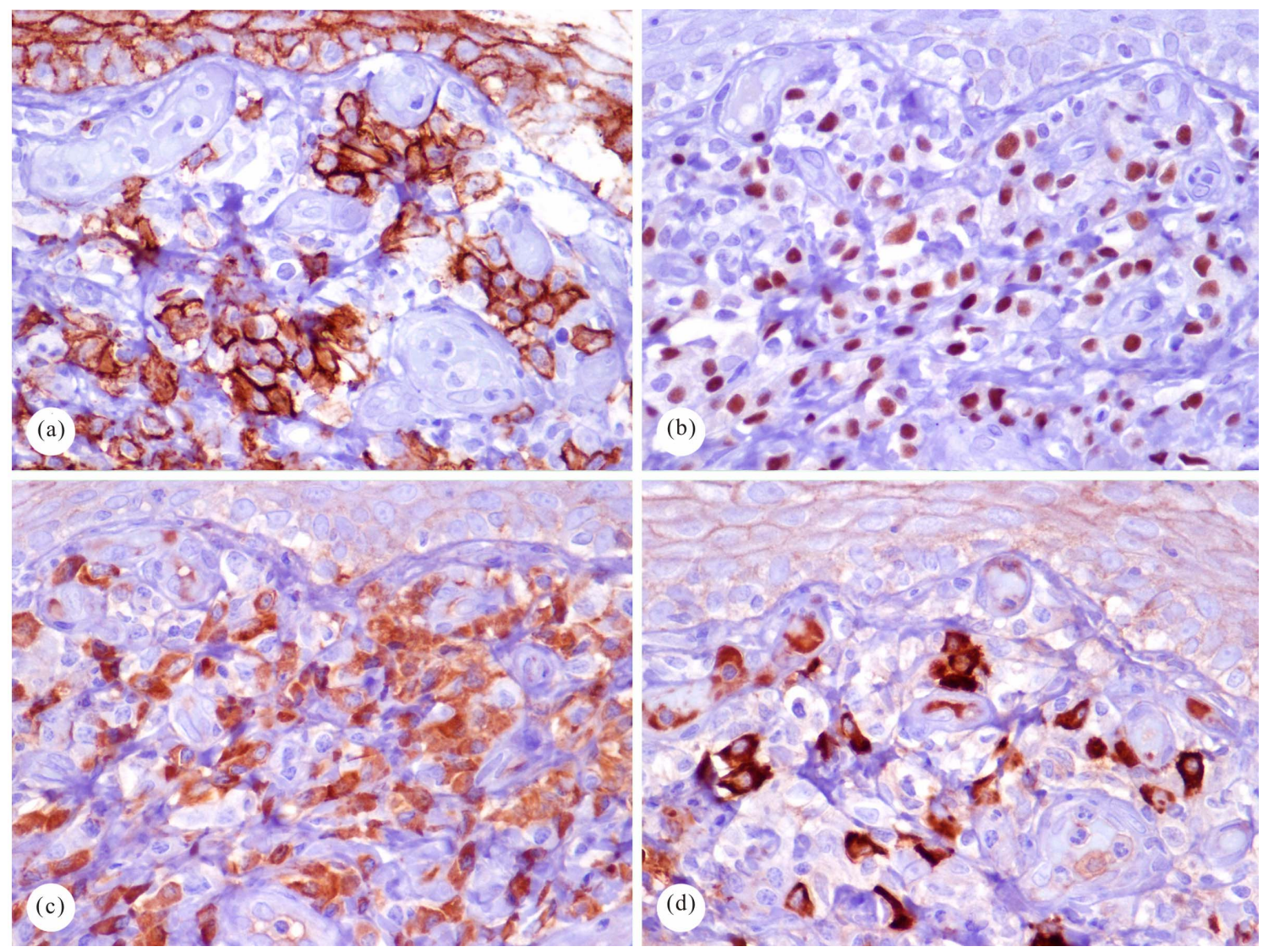

Figure 2. Immunohistochemical studies. CD138 $(\times 400,(\mathrm{a}))$ and Mum1 $(\times 400,(\mathrm{~b}))$ highlights the plasma cells in the dermis. (c) and (d), Kappa ( $\times 400,(c))$ and Lambda $(\times 400,(d))$ stains demonstrate a polyclonal plasma cell infiltrate in the dermis.

Table 1. Summary of reported cases with Zoon's balanitis and mucinous metaplasia.

\begin{tabular}{cccccc}
\hline Case & Age $(\mathrm{yr})$ & Duration & Anatomic location & Underlying disease & References \\
\hline 1 & 65 & $1 \mathrm{mo}$ & Glans penis and prepuce & Myotonic dystrophy & Val-Bernal et al. [1] \\
$2-5$ & 80 & Unknown & Glans penis and prepuce & Unknown & Fang et al. [2] \\
6 & 55 & $6 \mathrm{~ms}$ & Glans penis only & None & Ruiz-Genao et al. [3] \\
7 & 65 & $6 \mathrm{yr}$ & Glans penis and prepuce & Rosacea & Tong et al. [4] \\
8 & 40 & $2 \mathrm{yr}$ & Glans penis and prepuce & HCT $^{*}$ & Current case \\
\hline
\end{tabular}

*HCT: Hematopoietic cell transplantation.

clinical information, serology, and the $\mathrm{IgG} 4 / \mathrm{IgG}$ ratio do not support an IgG4 related disease. Although mucinous metaplasia is a benign process, Zoon's balanitis is often clinically suspicious for malignancy, and the clinical differential may include squamous cell carcinoma in situ, superficial spreading melanoma, and epidermoptropic metastases1. The histopathologic findings of Zoon's balanitis, may also overlap with other inflammatory or neoplastic conditions affecting the glans penis [7]. Clinical-Pathologic correlation is essential to establish the diagnosis.

In conclusion, Zoon's balanitis with mucinous met- aplasia is an exceedingly rare benign condition whose etiology, pathogenesis and clinical significance remain to be elucidated.

\section{REFERENCES}

[1] Val-Bernal, J.F. and Hernández-Nieto, E. (2000) Benign mucinousmetaplasia of the penis. A lesion resembling extramammary Paget's disease. Journal of Cutaneous Pathology, 27, 76-79. doi:10.1034/j.1600-0560.2000.027002076.x

[2] Fang, A.W., Whittaker, M.A. and Theaker, J.M. (2002) 
Mucinousmetaplasia of the penis. Histopathology, 40, 177-179. doi:10.1046/j.1365-2559.2002.01323.x

[3] Ruiz-Genao, D.P., Daudén-Tello, E., Adrados, M., Fraga, J. and García-Díez, A. (2004) Mucinousmetaplasia of the glans penis. Histopathology, 44, 90-91. doi:10.1111/j.1365-2559.2004.01754.x

[4] Tong, P.L., Delaney, T.A. and Beer, T.W. (2011) Erythematous shiny plaque over the glans penis-Quiz case. Archives of Dermatological, 147, 735-740. doi:10.1001/archdermatol.2011.129-a

[5] Wollina, U. (2010) Ablative erbium: YAG laser treatment of idiopathic chronic inflammatory non-cicatricial-bala- noposthitis (Zoon's disease)-A series of 20 patients with long-term outcome. Journal of Cosmetic and Laser Therapy, 12, 120-123. doi:10.3109/14764171003706125

[6] Marconi, B., Campanati, A., Simonetti, O., Savelli, A., Conocchiari, L., Santinelli, A., Pisa, E. And Offidani, A. (2010) Zoon'sbalanitis treated with imiquimod 5\% cream. European Journal of Dermatology, 20, 134-135.

[7] Weyers, W., Ende, Y., Schalla, W. And Diaz-Cascajo, C. Balanitis of zoon. The American Journal of Dermatopathology, 24, 459-467.

doi:10.1097/00000372-200212000-00001 